Macklem, P T (1975). The use of a helium-oxygen mixture during maximum expiratory flow to demonstrate obstruction in small airways in smokers. Journal of Clinical Investigation, 55, 1090-1099.

Fry, D L, and Hyatt, R E (1960). Pulmonary mechanics. American Journal of Medicine, 29, 672-689.

Hogg, J C, Macklem, P T, and Thurlbeck, W M (1968). Site and nature of airway obstruction in chronic obstructive lung disease. New England Journal of Medicine, 278, 1355-1360.

Macklem, P T (1972). Obstruction in small airwaysa challenge to medicine. American Journal of Medicine, 52, 721-724.

Mead, J, Turner, J M, Macklem, P T, and Little, J B (1967). Significance of the relationship between lung recoil and maximum expiratory flow. Journal of Applied Physiology, 22, 95-108.

Permutt, S, and Menkes, H A (1979). Spirometry: analysis of forced expiration within the time domain. In The Lung in the Transition between
Health and Disease, chapter 6 (Lung biology in health and disease series, vol 12), edited by $P$ Macklem and S Permutt. Marcel Dekker, New York.

Rosenblatt, G, and Stein, M (1962). Clinical value of the forced expiratory time measured during auscultation. New England Journal of Medicine, 267, 432435.

Tiffeneau, R, and Pinelli, A (1947). Air circulant et air captif dans l'exploration de la fonction ventilatrice pulmonaire. Paris Médical, 37, 624-628.

Tockman, M, Menkes, H, Cohen, B, Permutt, S, Benjamin, J, Ball, W C, jun, and Tonascia, J (1976). A comparison of pulmonary function in male smokers and non-smokers. American Review of Respiratory Disease, 114, 711-722.

Wright, B M, and McKerrow, C B (1959). Maximum forced expiratory flow rate as a measure of ventilatory capacity with a description of a new portable instrument for measuring it. British Medical Journal, 2, 1041-1047.

\title{
Digoxin for heart failure in sinus rhythm
}

Is digoxin useful in patients with heart failure who remain in sinus rhythm? This question is still being asked and may reflect the profound influence that MacKenzie and Lewis have had on British medicine. Generations of medical students were taught that digitalis was of little value unless the patient was in atrial fibrillation; it is certainly true that in their earlier writings both MacKenzie (1913) and Lewis (1933) avoided discussing the problem of the patient with heart failure in sinus rhythm. However, the beneficial effect of digitalis in these patients was shown in several studies (Christian, 1919; Harrison et al, 1931; Gavey and Parkinson, 1939; Wood, 1940), and by 1946 Lewis was able to write "Clear evidence that digitalis is useful in failure with congestion presenting normal rhythm has been slower in coming because success in such cases is less obvious and less frequent. Nevertheless it is now generally recognised that digitalis is valuable in these cases and sometimes succeeds in lowering the venous pressure and in bringing relief where other remedies have failed." But despite this, clinicians remained reluctant to use digoxin in these circumstances, no doubt because they had been taught otherwise at an impressionable age.

The fall in venous pressure and rise in cardiac output resulting from intravenous digoxin in patients with heart failure was confirmed by McMichael and Sharpey-Shafer (1944). The cardiac output fell in normal subjects and in those with cor pulmonale, and at that time it was thought the primary action of digoxin was to lower the venous pressure. Although these authors subsequently revised their opinion, the difficulty in showing a positive inotropic effect with the techniques then available led McMichael to state in 1952 "Digitalis has no measurable effect on the contractile force of a normally functioning myocardium" (McMichael, 1952). This statement is still remembered and, moreover, the idea that digoxin might actually be harmful to patients with cor pulmonale (Howarth et al, 1948) means that its use is often restricted to those patients with atrial fibrillation.

The development of more sensitive techniques for measuring the force of ventricular contraction in man allowed Braunwald and his colleagues to show the positive inotropic effect of digoxin on the non-failing human heart by various means, including strain gauges attached to the myocardium during cardiac operations (Braunwald et al, 1961), the measurement of peak left ventricular $\mathrm{dp} / \mathrm{dt}$ using a catheter tip manometer (Mason and Braunwald, 1963) and the use of ventricular markers to study myocardial force-velocity relations (Sonnenblick et al, 1966). Nowadays the acute positive inotropic effect of digoxin on both the failing and non-failing human heart cannot be doubted. The measurement of systolic time intervals and the ball travel time of an aortic Starr valve also reflect the contractile state of the left 
ventricle in man, and these techniques have been used to confirm the positive inotropic effect of digoxin in short-term experiments (Weissler et al, 1966; Davidson and Gibson, 1973). The acute inotropic effect is relatively weak, as compared with isoprenaline in the dog heart (Beiser et al, 1970), and is equivalent to the effect of mild exercise in man (Davidson and Gibson, 1973).

It is more difficult to show that this positive inotropic effect is sustained during maintenance therapy with digoxin (Weissler et al, 1966; Davidson and Gibson, 1973). There are two possible reasons for this, one being the relative insensitivity of the techniques available and the other the reflex changes in the cardiovascular system, such as a reduction in cardiac sympathetic tone, which may mask the effect of the digoxin. Despite these reservations at least three groups of workers have shown a sustained improvement in systolic time intervals which appears to be dose-related (Carliner et al, 1974; Hoeschen and Cuddy, 1975; Dobbs et al, 1977). Vogel et al (1977) have used echocardiography to study changes in left ventricular performance and have confirmed the beneficial effects of digitalis. A single dose of ouabain resulted in an increase in left ventricular ejection fraction in patients with coronary artery disease both at rest and after isometric exercise. After two weeks' treatment with digoxin this effect could not be shown at rest but could be brought out by the stress of isometric exercise.

So it would appear that digoxin does have a measurable long-term positive inotropic effect on ventricular muscle, which supports the earlier clinical observations quoted above. Matters might be left there were it not for the high incidence of side effects in patients receiving digoxin, particularly among the elderly. For example, Carruthers et al (1974) found that 13 out of 101 patients who were taking digoxin when admitted to hospital had symptoms or cardiac dysrhythmias that resolved when this drug was stopped. Beller et al (1971) in a similar study found that 31 out of 135 patients taking digoxin showed toxic effects, and that the mortality rate was higher in this group than in the remainder who did not show toxic effects.

The danger of digoxin in elderly patients was appreciated by Dall (1970) who pointed out that maintenance digoxin could often be stopped. This finding was confirmed in patients in general practice (Hull and Mackintosh, 1977) and in patients after an episode of heart failure (Dobbs et al, 1977). It is difficult to escape the conclusion that some of these patients were receiving digoxin unnecessarily. It is also true that many patients with heart failure in sinus rhythm can be managed perfectly well using modern diuretics alone (McHaffie et al, 1977).

So when should digoxin be given to patients with heart failure who remain in sinus rhythm? First it should be reserved for those patients with myocardial failure. Digoxin cannot be expected to help those with mitral stenosis or hypertrophic cardiomyopathy, or those whose ankle oedema is due to other causes. Hence a proper cardiac diagnosis is vital.

In patients with heart failure caused by valve disease the results of surgical treatment, even in the elderly (De Bono et al, 1978), are now so good that this treatment is to be preferred. Digoxin can be used in patients who are not suitable for valve surgery or in those in whom valve surgery has been unsuccessful, if there is reason to suspect additional myocardial damage. It is not easy to decide when these patients will benefit from digoxin, and each case must be judged on its merits. The use of digoxin in younger patients with valve disease is to be deprecated because digoxin will cause electrocardiographic $T$ wave changes, which will make it more difficult to follow the natural history of the valve lesion and to choose the correct time for valve replacement. Thus digoxin is of limited value in patients whose myocardial failure is secondary to the pressure or volume overload of valve disease. This argument may be extended to patients with hypertension, congenital heart disease, or cor pulmonale; the primary treatment should be directed towards the underlying cause of the heart failure, and digoxin should be used sparingly. In practice this means that it should be given at a late stage to those with cor pulmonale or irremediable cardiac defects, and for a limited time to infants with congenital heart disease whose heart failure will improve as they grow-for example, those with ventricular septal defects. In patients with high blood pressure digoxin may be needed initially, but it can be stopped once the pressure is controlled.

This leaves those patients whose heart failure is caused by ischaemic or primary myocardial disease whose symptoms and signs cannot be controlled with a diuretic alone; these should receive digoxin. Long-term treatment may not be necessary if spontaneous improvement can be expected-for example, after cardiac infarction when compensatory hypertrophy will occur, or when the failure has been exacerbated by some other disease such as a chest infection. In the remainder digoxin should be used for its inotropic effect together with a diuretic to alleviate the symptoms of fluid retention. If the failure is easily 
controlled then an attempt may be made to stop the digoxin. In those with persisting cardiomegaly and gallop rhythm digoxin should be continued indefinitely.

Perhaps the future will bring us a safer alternative oral agent with a sustained positive inotropic effect, but until that time digoxin should be used in patients in sinus rhythm with myocardial failure.

M C PETCH

Regional Cardiac Unit, Papworth Hospital, Papworth Everard, Cambridge CB3 8RE

\section{References}

Beiser, G D, Epstein, S E, Goldstein, R E, Stampfer, $M$, and Braunwald, E (1970). Comparison of the peak inotropic effects of a catecholamine and a digitalis glycoside on the intact canine heart. Circulation, 42, 805-813.

Beller, G A, Smith, T W, Abelmann, W H, Haber, E, and Hood, W B (1971). Digitalis intoxication. A prospective clinical study with serum level correlations. New England Journal of Medicine, 284, 989997.

Braunwald, E, Bloodwell, R D, Goldberg, L I, and Morrow, A G (1961). Studies on digitalis. IV. Observations in man on the effects of digitalis preparations on the contractility of the non-failing heart and on total vascular resistance. Journal of Clinical Investigation, 40, 52-59.

Carliner, N H, Gilbert, C A, Pruitt, A W, and Goldberg, L I (1974). Effects of maintenance digoxin therapy on systolic time intervals and serum digoxin concentrations. Circulation, 50, 94 98.

Carruthers, S G, Kelly, J G, and McDevitt, D G (1974). Plasma digoxin concentrations in patients on admission to hospital. British Heart Journal, 36, 707-712.

Christian, H A (1919). Digitalis therapy: satisfactory effects in cardiac cases with regular pulse-rate. American Journal of the Medical Sciences, 157, 593-603.

Dall, J L C (1970). Maintenance digoxin in elderly patients. British Medical Journal, 2, 705-706.

Davidson, C, and Gibson, D (1973). Clinical significance of positive inotropic action of digoxin in patients with left ventricular disease. British Heart Journal, 85, 970-976.

De Bono, A H B, English, T A H, and Milstein, B B (1978). Heart valve replacement in the elderly. British Medical Journal, 2, 917-919.

Dobbs, S M, Kenyon, W I, and Dobbs, R J (1977). Maintenance digoxin after an episode of heart failure: placebo-controlled trial in outpatients. British Medical Journal, 1, 749-752.

Gavey, C J, and Parkinson, J (1939). Digitalis in heart failure with normal rhythm. British Heart Journal, 1, 27-44.

Harrison, T R, Calhoun, L A, and Turley, F C (1931). Congestive heart failure. XI. The effect of digitalis on the dyspnoea and on the ventilation of ambulatory patients with regular cardiac rhythm. Archives of Internal Medicine, 48, 1203-1216.

Hoeschen, R J, and Cuddy, T E (1975). Dose response relation between therapeutic levels of serum digoxin and systolic time intervals. American Journal of Cardiology, 35, 469-472.

Howarth, S, McMichael, J, and Sharpey-Shafer, E P (1948). Effects of oxygen, venesection and digitalis in chronic heart failure from disease of the lungs. Clinical Science, 6, 187-196.

Hull, S M, and Mackintosh, A (1977). Discontinuation of maintenance digoxin therapy in general practice. Lancet, 2, 1054-1055.

Lewis, T (1933). Diseases of the Heart. Macmillan, London.

Lewis, T (1946). Diseases of the Heart, 4th edn. Macmillan, London.

McHaffie, D J, Purcell, H, Mitchell-Heggs, P, and Guz, P (1977). Are digitalis glycosides of benefit to the patient in sinus rhythm with cardiac failure due to myocardial disease? Quarterly Journal of Medicine, 46, 557-558.

Mackenzie, J (1913). Diseases of the Heart, 3rd edn. Henry Frowde, London.

McMichael, J (1952). Dynamics of heart failure. British Medical Journal, 2, 525, 578-582.

McMichael, J, and Sharpey-Shafer, E P (1944). The action of intravenous digoxin in man. Quarterly Journal of Medicine (NS), 13, 123-135.

Mason, D T, and Braunwald, E (1963). Studies on digitalis. IX. Effects of ouabain on the non-failing human heart. Journal of Clinical Investigation, 42, 1105-1111.

Sonnenblick, E H, Williams, J F, Glick, G, Mason, D T, and Braunwald, E (1966). Studies on digitalis. XV. Effects of cardiac glycosides on myocardial force-velocity relations in the non-failing human heart. Circulation, 34, 532-539.

Vogel, R, Frischknecht, J, and Steele, P (1977). Shortand long-term effects of digitalis on resting and posthandgrip hemodynamics in patients with coronary artery disease. Amercian Journal of Cardiology, 40, 171-176.

Weissler, A M, Syder, J R, Schoenfeld, C D, and Cohen, S (1966). Assay of digitalis glycosides in man. American Journal of Cardiology, 17, 768-780.

Wood, P (1940). The action of digitalis in heart failure with normal rhythm. British Heart Journal, 2, 132140. 